\title{
SOCIALIZAÇÃO E VIDA COTIDIANA: UM NOVO CAMINHO INTERPRETATIVO
}

\author{
SOCIALIZATION AND EVERYDAY LIFE: A NEW INTERPRETATIVE PATH
}

SOCIALIZACIÓN Y VIDA COTIDIANA: UNA NUEVA FORMA INTERPRETATIVA

\author{
ADRIANA BOZZETTO ${ }^{1}$ \\ ORCID: https://orcid.org/0000-0002-2961-8651
}

SETTON, Maria da Graça Jacintho (Org.). Sociologia da Socialização: novos aportes teóricos. São Paulo: FEUSP, 2018. 253 p.

Vivemos tempos duros e de incertezas ${ }^{2}$. O livro de Graça Setton e dos autores que o integram, aponta para algumas misérias do mundo contemporâneo, fazendo jus ao livro que Bourdieu ${ }^{3}$ organizou. A partir de cuidadoso e atento colchão teórico, sobre o qual as pesquisas empíricas aqui abordadas repousam sem perder a hora, o livro não se priva de uma crítica social ao mundo em questão.

Desvelando espaços de socialização que nos desafiam a pensar lugares e tempos em que formamos nossas referências identitárias na contemporaneidade, enquanto atores sociais que também modificam esses espaços, os artigos apontam quadros de socialização que permitem um panorama de uma paisagem ainda excludente, discriminatória e desigual. Para modificar essa realidade "dura e incerta" em que homens, mulheres, crianças e jovens são expostos a viver e a lutar, é preciso estudos que nos permitam, em primeiro lugar, compreender o mosaico da vida social através de pesquisas solidamente integradas no GPS - Grupo de Práticas de Socialização Contemporâneas da Universidade de São Paulo.

Um fio condutor une os textos aqui apresentados, na perspectiva de um olhar crítico e afiado que não se contenta em revelar, mas problematizar. Já na abertura, Maria da Graça Jacintho Setton, organizadora da obra, nos convida a pensar o "novo", no sentido de caminhos interpretativos e suportes teóricos que permitam reinventar uma análise plural desses processos socializadores e, portanto, educativos. Ao mesmo tempo, a autora nos coloca frente ao desafio de pensar o papel ativo e reflexivo da educação e das múltiplas instâncias socializadoras da contemporaneidade. Lançando a ideia central da contribuição desta obra, a autora e organizadora vai construindo sua proposição teórica em torno das disposições híbridas de habitus, tema recorrente em todos os capítulos. Nessa dimensão, não há contradição nos repertórios construídos de socialização dos indivíduos. Por serem disposições tecidas em diferentes oportunidades e esferas, em condições de reflexividade, o indivíduo negocia e/ou obedece, inova e/ou reproduz, deixando ao estudioso da sociologia da educação a curiosidade pela compreensão dos movimentos complexos e difusos da vida de cada um. Por isso, também, faz-se necessário conhecer uma única trajetória, um caso, um espaço socializador. Todos carregam a pluralidade e as marcas das instâncias de socialização contemporâneas, em processos difusos e complexos que não concebem a separação entre indivíduo e sociedade.

Dividido em três partes, "SOCIOLOGIA DA SOCIALIZAÇÃO: NOVOS APORTES TEÓRICOS" é constituído de doze artigos, frutos de trabalhos realizados dentro do Curso de Pós-

\footnotetext{
${ }^{1}$ Universidade Federal do Pampa. Bagé, RS, Brasil. <adrianabozzetto@unipampa.edu.br>

${ }^{2}$ Em alusão ao tema do VI Colóquio Luso-Brasileiro de Sociologia da Educação (Universidade do Minho, Braga/Portugal), onde o ebook foi lançado em 26 de novembro de 2018.

${ }^{3}$ Refiro-me ao livro "A Miséria do Mundo", coordenado por Pierre Bourdieu.
} 
Graduação da Faculdade de Educação da Universidade de São Paulo, na linha de pesquisa "Ciências Sociais: desigualdades e diferenças".

A primeira parte do livro, intitulada "SOCIALIZAÇÃO INFORMAL", trata de uma apresentação sobre "O processo de socialização contemporâneo - revisitando algumas proposições", de Maria da Graça Jacintho Setton. O texto abre os trabalhos que virão ambientando e esclarecendo a compreensão do termo socialização e como tem sido abordado no campo sociológico. A exemplo, a autora provoca a reflexão sobre espaços socializadores contemporâneos como as mídias, tratadas de forma ainda muito tímida, e a religião, praticamente relegada a um plano inferior. Todos os capítulos, conforme Setton enfatiza, entendem socialização "como processos de integração e negociação" (p. 08), em movimento entre as macro e micro instituições.

No segundo artigo, “A socialização na cidade: notas sobre a migração nordestina em São Paulo", Adriana Dantas descortina aspectos biográficos de um baiano na capital paulistana, desvelando uma socialização marcada por tentativas e erros que deram certo, mas que poderiam "não ter dado". Através de um único estudo de caso, suficiente para uma análise fecunda, acompanhamos traços de uma socialização marcada, por vezes, pela discriminação e violências simbólicas que marcam uma trajetória individual e, portanto, social. O texto revela estratégias de viver e se constituir em um espaço territorialmente abundante e prenhe de desafios com os quais a classe de migrantes se confronta, em busca de trabalho e direitos que permitam, através de novas experiências socializadoras, a quebra de processos de permanência da desigualdade.

As autoras Mylene Nogueira Teixeira e Maria da Graça Jacintho Setton tratam, no terceiro texto, das "Feministas no sertão: percursos emancipatórios". Neste trabalho, as autoras discutem o processo de construção de um conjunto de disposições de gênero de um grupo de mulheres que se reconhecem feministas, movimentando-se enquanto líderes intelectuais. Essas mulheres, todas com uma infância marcada pela pobreza no sertão nordestino, subverteram a ordem reprodutiva e, apesar de exemplos que apontam o quanto se sentiram exploradas, conseguiram fazer mutirões pela solidariedade, ao se colocarem no lugar do outro. $\mathrm{O}$ artigo também trouxe algumas informações acerca de um universo social bastante específico, desvelando nuances de trajetórias de vida muito semelhantes dessas líderes feministas, em percursos marcados pela busca de uma emancipação social em projetos que contemplam, dentre outros, o combate à violência contra a mulher.

A primeira parte do livro se encerra com o estudo de pós-doutorado de Mirtes Marins de Oliveira, "Display como estratégia educacional e roteiro crítico para visitar exposições". Característica de uma pedagogia modernista, o display como roteiro às visitações de museus apresenta movimentos tanto de inclusão, ao oportunizar múltiplos elementos de comunicação, quanto de exclusão, ao tentar definir um olhar que permita ao público captar a obra seguindo narrativas de convencimento. Nessa linha condutora, as percepções plurais dos visitantes (e mesmo seus distintos contextos culturais) perdem força para uma suposta objetividade e segurança, que desperdiçaria o potencial imaginativo de quem transita pelas obras de um museu. Para discutir essas questões, a autora constrói um panorama consistente de autores que nos permitem a compreensão de um histórico sobre essas práticas culturais, contribuindo para uma leitura atenta sobre a função didática das visitações às exposições, ampliando e dando visibilidade a outros espaços de socialização da vida contemporânea.

No miolo do livro, outra perspectiva é delineada. A parte dois do ebook trava uma discussão acerca de pensar a "SOCIALIZAÇÃO E MÍDIAS", uma das marcas identitárias do grupo de pesquisa, ao problematizar essa instância socializadora, que dinamiza as relações entre escola e família, espaços de tradição nos estudos sobre socialização no campo da educação. O texto "A socialização da e na infância", baseado em parte dos resultados da pesquisa de doutorado de Lisandra Ogg Gomes, desvela uma crescente atenção ao mundo infantil como um mundo não inacabado, mas que carrega em seu contexto a totalidade própria da categoria ser criança, atores sociais imprescindíveis para a construção e compreensão da sociedade. Através de imersão etnográfica realizada no contexto de uma escola pública de educação infantil na cidade de Campinas, SP, ao longo de um ano letivo, a autora realizou observações e entrevistas com crianças e adultos. A análise e interpretação dos dados desvelam processos de socialização que circulam pelas agências escolares, midiáticas, nos grupos de pares e na família. Nas entrelinhas reveladas dessa ciranda infantil em que as crianças constroem saberes, gostos, discursos e preferências, a autora salienta o movimento desta categoria social, destacando a criança como um ser 
ativo e em interdependência com a complexidade social da qual é integrante. Compreender esses engendramentos que envolvem várias instâncias socializadoras "precisa ser conhecido a fim de serem revistos conceitos e práticas para com as crianças e a infância” (GOMES, 2018, p. 91).

Pulando da infância para o universo juvenil, Vanessa Teixeira Pipinis apresenta "O Brasil pelos olhos dos jovens: a construção da identidade nacional a partir da mídia e da escola", com a premissa de que um possível retrato do país é construído a partir de uma miríade de espaços socializadores nos quais os jovens constroem suas representações. A autora inicia o capítulo resgatando contribuições de autores que são referenciais no campo da Sociologia da Educação, orientando para uma transformação do entendimento de socialização de Émile Durkheim a autores como Peter Berger e Thomas Luckmann, além de Bernard Lahire e Maria da Graça Setton. Portanto, a partir das esferas tradicionais - família e escola, em direção à compreensão de outros espaços em que as mídias se movem como um campo fecundo de análise dos processos socializadores no mundo atual. $\mathrm{O}$ trabalho de campo envolveu a produção de 23 cartas escritas por jovens estudantes do último ano do ensino médio, motivados por uma apresentação do seu país a algum amigo/a que nunca ouviu falar do Brasil. Nestas representações, aparecem imagens inventariadas a partir de um repertório particularmente construído no cotidiano da instituição escolar e através das mídias, revelando imaginários que polarizam um Brasil belo e exuberante em contraste com aquele noticiado como violento, vulnerável e corrupto:

Se as disposições éticas e estéticas que as mídias disponibilizam apresentam um certo choque entre Brasis, a participação da escola na construção desse imaginário é fundamental; embora as formulações de disposições de habitus contemporâneos sejam híbridas, ainda assim é possível haver hierarquias entre elas. Justamente, nesse sentido, destaca-se o papel relevante da escola, na perspectiva de generalizar o acesso a disposições de cultura e imprimir em sua clientela a capacidade reflexiva (PIPINIS, 2018, p. 116-117).

As instâncias socializadoras da contemporaneidade, notadamente representadas pelas mídias, ganham visibilidade nestas pesquisas que consideram sua complexidade e a indissociabilidade entre indivíduo e sociedade. Estes trabalhos tocam em um ponto espinhoso nas discussões sobre os processos educativos de crianças e jovens através das mídias, deslocando a atenção das instituições tradicionais que objetivam a educação para uma escuta atenta dos atores sociais. Mais que necessário, é urgente escutar as ideias e concepções destas categorias sociais que são o presente e futuro da sociedade que se encontra frente a incontáveis desafios cotidianos. Compreendendo que a relação educativa implica interação e um conjunto histórico de experiências socializadoras realizadas nos espaços aqui discutidos, começa a ganhar fôlego uma nova compreensão do que é ser criança, jovem e adulto em uma sociedade marcada pela crescente rede de informações de todas as ordens. Vale lembrar que estudar a infância e a juventude implica o estudo de outro conjunto de espaços socializadores: a família, a escola, as novas ferramentas midiáticas e seus impactos na formação de sensibilidades e repertórios contemporâneos.

Avançando em direção a um aprofundamento analítico dos processos sociais contemporâneos, Michelle Prazeres aborda o "Sociorreferenciamento: uma ferramenta teóricometodológica para analisar as relações entre campos, partindo das interações entre a educação e as tecnologias". Neste artigo, o objeto de análise é um conjunto de documentos publicados pelo Estado, Mídia, Universidade e Empresa, quatro campos que possibilitam o mapeamento de valores carregados de um conjunto de socializações difusas, característica de uma fusão de agentes que constroem concepções sobre o que seria uma moderna socialização escolar.

Os dois capítulos finais deste eixo abordam práticas culturais e disposições híbridas de habitus em dois contextos diversos: do Jornalismo e da Licenciatura em Música. Ao abordar a categoria profissional de jornalistas da educação, no texto "Matrizes socializadoras e disposições de habitus: considerações sobre os jornalistas brasileiros", Rodrigo Ratier enfatiza mais especificamente duas instâncias de socialização nas referências identitárias dos entrevistados - a familiar e a cultural. O autor discute que essas instâncias permitem o conhecimento de um conjunto de influências difusas que têm impacto direto na constituição das identidades profissionais dos jornalistas. O apoio detalhado das famílias e as práticas culturais envolvidas em períodos de longa duração, apontando a categoria tempo como importante leitura dos processos socializadores, contribuem para o argumento que "nenhuma instituição detém o monopólio da socialização dos indivíduos, que se socializam ativamente, sendo o 
lugar de encontro e ressignificação da multiplicidade de influências advindas dos mais variados laços sociais" (RATIER, 2018, p. 156-7).

No capítulo de Paula Alexandra Reis Bueno, temos acesso às "Disposições híbridas nos gostos culturais de licenciandos em música". Considerando que os gostos culturais destes jovens constituem disposições de habitus (Bourdieu, 2012) incorporadas ao longo da trajetória de vida, desde as memórias musicais da infância que envolve o universo familiar às escutas musicais operacionalizadas pelas novas tecnologias, é possível entender por quais motivos, gosto se discute. Circulando por condições de socialização que mesclam referenciais diversos, uma Análise de Correspondências Múltiplas demonstrou "que a divisão entre gêneros musicais populares e eruditos continuam permeando imaginários e representações" (BUENO, 2018, p. 176). Desta forma, apresenta-se a organização de tipos de gosto musical, que em suas nuances e através de diversas instituições, com a análise de um generoso leque de informações, nos convida a refletir a respeito da construção social do gosto musical em sua complexidade de oportunidades.

Por fim, e não menos importante, o livro apresenta outra instância marcada pela emergência de um pensamento crítico e reflexivo: o espaço socializador das religiões. A parte três, dedicada ao eixo temático "Socialização e Religião", discute o lugar dessa instância de socialização no âmbito docente e da juventude. Estes estudos somam um olhar para o papel da religião enquanto experiência formativa, que "orienta condutas, seleciona novos aprendizados e interfere na socialização" (KNOBLAUCH, 2018, p. 207).

O texto "A indissociabilidade de características identitárias dos professores: entre disposições seculares e religiosas", de Gabriela Abuhab Valente, remete à análise de como os docentes concebem o tema da religiosidade na escola, revelando, através de suas práticas sociais e modos de pensar a religião, os valores incorporados, com base em diferentes matrizes de cultura, mas mantidos em torno da fé cristã. O estudo desnaturaliza crenças e ações cotidianas dos professores na escola, oportunizando reflexões para identidades forjadas, a partir de disposições híbridas de habitus, em múltiplos espaços socializadores responsáveis por essas visões de mundo. A autora alerta para o modo como essas disposições geram indissociabilidade entre religião e práxis profissional, defendendo que se faz necessário admitir a existência deste componente na cultura escolar e aproveitá-lo para desvelar preconceitos e intolerâncias, assim como promover reflexões sobre a temática.

$\mathrm{Na}$ mesma perspectiva em relação à docência, Adriane Knoblauch aborda os "Intercâmbios e hibridismos entre formação docente e religião". A autora discute aspectos referentes à socialização profissional de três estudantes em interface com a religião, destacando processos de hibridização entre essas esferas. Valores, condutas, modos de pensar e agir, mesmo que já naturalizados, são colocados em discussão para se pensar a não neutralidade do conteúdo religioso na socialização de futuras professoras.

Caminhando para o capítulo final, "A religião como matriz de práticas de socialização da juventude e sexualidade" é abordada por Elias Evangelista Gomes. Retomando com clareza as discussões propostas por Setton, das disposições híbridas de habitus que se constituem na e da participação ativa do indivíduo na construção social de sua relação com o mundo, a partir das referências culturais que tem disponíveis, Gomes (2018) propõe considerarmos a religião como uma das principais matrizes de cultura que, junto a outras instâncias socializadoras, elabora "mecanismos de controles das condutas e dos modos de ser, pensar e agir de um contingente significativo da população" (GOMES, 2018, p. 251). Nessa direção, as reflexões sobre a socialização de jovens na religião ocorrem a partir da busca por compreender os modos de educar e controlar a sexualidade dos sujeitos.

Finalmente, o livro provoca a pensar, afinal, por que estes temas são importantes? Para que são úteis? Talvez por aproximar o cientista social, no campo da educação, da tarefa prática em denunciar as violências simbólicas que assombram e contribuem para uma vida dura e incerta. Talvez por buscar respostas a situações socializadoras que nos desafiam, enquanto professores universitários e membros privilegiados de um ambiente acadêmico, e nos libertarmos de uma fictícia zona de conforto. Qualquer que seja o ambiente socializador em estudo, os textos aqui reunidos têm como leitmotiv um empenho analítico que provoque atenção às realidades construídas, reforçadas e reproduzidas da cena social. Quebrar as invisíveis telas que protegem sempre os mesmos, e lutar pelo mundo social que utopicamente acreditamos, não é tarefa ingênua. É necessário, sobretudo, pesquisas empíricas, esforços analíticos e (re)invenções teóricas para que o invisível, o esquecido, o anônimo, tenham dignamente um lugar em 
nossas discussões e propostas de mudança. Esse, o ponto mais nevrálgico, mas que nos move a ter esperança na transformação pela educação.

Todos os artigos do livro trabalham com a ideia teórica proposta por Setton, qual seja, as disposições híbridas de habitus. Nessa perspectiva, as realidades empíricas estudadas nas pesquisas aqui reunidas contribuem para reforçar um olhar em que, na contemporaneidade, os indivíduos sentem-se forçados a mesclar disposições de cultura de uma grande quantidade e diversidade de instâncias socializadoras. Nesta proposição, a contribuição de novos aportes teóricos se concretiza e abre janelas para a continuidade e adensamento de pesquisas que possam trazer outros "quadros, modalidades, tempos e efeitos de socialização" (LAHIRE, 2015), refinados por olhares sensíveis, críticos e problematizadores. Estes, presentes nos mais inusitados temas e espaços da vida cotidiana, e que merecem nossa atenção.

\section{REFERÊNCIAS}

BOURDIEU, Pierre; CHARTIER, Roger. O sociólogo e o historiador. Belo Horizonte: Autêntica Editora, 2012.

LAHIRE, Bernard. A fabricação social dos indivíduos: quadros, modalidades, tempos e efeitos de socialização. Educação e Pesquisa, São Paulo, v. 41, n. especial, p. 1393-1404, dez. 2015.

SETTON, Maria da Graça Jacintho (Org.). Sociologia da Socialização: novos aportes teóricos. São Paulo: FEUSP, 2018. 253 p.

Submetido: 06/05/2019

Aprovado: 06/09/2020 